(C) 2020, The Authors. Published by Elsevier Inc. and Fass Inc. on behalf of the American Dairy Science Association ${ }^{\circledR}$. This is an open access article under the CC BY-NC-ND license (http://creativecommons.org/licenses/by-nc-nd/4.0/).

\title{
Milk lactoferrin concentration of primiparous and multiparous sows during lactation
}

\author{
M. Jahan, ${ }^{1,2}$ (i) N. Francis, ${ }^{2}$ and B. Wang ${ }^{1,2 *}$ (]) \\ ${ }^{1}$ Graham Centre for Agricultural Innovation, Charles Sturt University, Wagga Wagga, NSW 2650, Australia \\ ${ }^{2}$ School of Animal and Veterinary Sciences, Charles Sturt University, Wagga Wagga, NSW 2678, Australia
}

\section{ABSTRACT}

Lactoferrin (LF), a sialylated iron-binding glycoprotein, has numerous vital physiological functions including immunomodulation and protection against a large group of microorganisms, improving neurodevelopment, health, growth performance, and milk production. Lactoferrin occurs in human milk at a higher concentration compared with bovine milk, but little information is available on LF concentrations in porcine milk and the effects of sow parity on milk LF concentration. The objective of this study was to quantify the LF concentration in porcine milk and to compare that concentration between gilts and sows during lactation. We also investigated the effect of genetic background and litter size of the female pig on the LF concentration of porcine milk. The milk from 30 gilts and 35 sows was collected at 3 stages of lactation, namely colostrum, transition, and mature milk. Standard and experimental samples were analyzed by ultra-high performance liquid chromatography using a diode array UV detector. The following findings were reported: (1) porcine milk contained significant levels of LF with the highest concentration in colostrum, which decreased by $\sim 62 \%$ and $\sim 67 \%$ in transitional and mature milk, respectively; (2) mature gilt milk contained a $22 \%$ higher concentration of LF compared with sow milk, which was statistically significant; (3) breed line had an overall significant effect on the LF content of porcine milk; however, when the breed was considered, no significant difference was observed; and (4) LF concentration of porcine milk was not significantly influenced by the litter size. The presence of LF in a higher concentration in porcine milk suggests that LF is an important constituent of pig milk that might contribute to the optimum growth and development of piglets.

Key words: lactoferrin, milk, lactation, breed line, pig

Received January 2, 2020.

Accepted March 18, 2020.

*Corresponding author: biwang@csu.edu.au

\section{INTRODUCTION}

Lactoferrin (LF), an iron-binding sialylated glycoprotein, is present in secretions such as milk, tears, saliva, gastric juice, and seminal fluids (Cheng et al., 2008; González-Chávez et al., 2009; Wang, 2016). Lactoferrin was first isolated in 1939 as a red protein from the whey of bovine milk (Sorensen and Sorensen, 1940). Later, LF was purified as a major iron-binding glycoprotein in the milk of humans and other species (Groves, 1960). Many studies have documented that LF modulates the overall immune system and is involved in the defense response of the host against a spectrum of bacteria, fungi, yeasts, viruses, and parasites (González-Chávez et al., 2009). Lactoferrin also stimulates the growth of probiotic bacteria in the gut, including Lactobacillus and Bifidobacter, and promotes gut development (Wang et al., 2019). Other functions of LF include its involvement in iron homeostasis in the intestine, enhancement of skeletal growth, and anti-cancerous activities in humans (Jahan et al., 2017). Furthermore, dietary LF intervention upregulates the expression of brain-derived neurotrophic factors, ubiquitin carboxyterminal hydrolase L1, and alkaline phosphate activity to reduce early weaning diarrhea (Yang et al., 2014). Maternal and postnatal LF intervention also promotes early neurodevelopment, neuroprotection, and cognition in postnatal piglets and rodent (Somm et al., 2014; Chen et al., 2015; Jahan et al., 2017). In humans, LF provides protection to infants born with low birth weight by reducing the risk of invasive fungal infection (Manzoni et al., 2012; Jahan et al., 2017). Overall, LF has multifunctional health benefits for both humans and animals.

The concentration of LF in milk varies across species (Masson and Heremans, 1971). For instance, in human milk LF appears as a major milk whey protein with a concentration of up to $7 \mathrm{mg} / \mathrm{mL}$ in the colostrum and $2 \mathrm{mg} / \mathrm{mL}$ in mature milk (Nguyen et al., 2014). However, it is present as a minor protein in bovine milk where its concentration is about 1.5 and $0.2 \mathrm{mg} / \mathrm{mL}$ in the colostrum and mature milk, respectively (Nguyen 
et al., 2014). In other dairy species such as goats, the LF concentration is about $0.39 \mathrm{mg} / \mathrm{mL}$ in colostrum and $0.06 \mathrm{mg} / \mathrm{mL}$ in mature milk (Hiss et al., 2008). However, in buffalo and camel milk, the LF concentration varies from 0.03 to $0.81 \mathrm{~g} / \mathrm{kg}$ and 0.59 to $1.42 \mathrm{mg} /$ $\mathrm{mL}$, respectively (Konuspayeva et al., 2007; Giacinti et al., 2013). Lactoferrin is also known to be present in guinea-pig milk (Masson and Heremans, 1971). However, milk from rats, rabbits, and dogs was found to be devoid of LF (Masson and Heremans, 1971).

Studies show that many factors influence the concentration of LF in milk, such as the stage of lactation, the age and nutritional status of the sow, the season of the year, and the daily amount of milk production (Gallagher et al., 1997). Parity also influences LF concentration in cow milk (Cheng et al., 2008). In cows, the highest concentrations of LF have been observed in parities 3,4 , and 5 compared with parities 1 and 2 (Cheng et al., 2008). An increased serum and milk LF concentration was reported in postpartum inflammatory disease of the udder (Yang et al., 2000). In humans, maternal infections, acute febrile illnesses from the urinary tract, upper respiratory and gastrointestinal infections, or infections on the skin may result in lower concentrations of milk LF (Rai et al., 2014).

Problems such as pre-weaning mortality, reduced growth performance, preterm births, and still births, as well as a high prevalence of infectious diseases are common in the swine industry, and particularly in primiparous sows (Cebulska et al., 2012; Václavková et al., 2012; Jahan et al., 2017). Moreover, intrauterine growth restriction (IUGR), a condition where the fetus does not grow at the expected rate during pregnancy, has led to higher levels of perinatal mortalities and morbidity associated with reducing the efficiency of feed utilization, as well as poor postnatal growth, even resulting in permanent stunting in pigs. About 15 to $20 \%$ of piglets are born with IUGR and have a birth weight $<1.1 \mathrm{~kg}$ compared with a normal birth weight of $1.4 \mathrm{~kg}$ (Wu et al., 2006). The progeny of primiparous sows are comparatively smaller than those of multiparous sows; also a higher incidence of IUGR has been observed in primiparous sows (McMillen and Robinson, 2005; Smits, 2011; Jahan et al., 2017). Recently, it has also been reported that early development in gilt progeny may be delayed in comparison to sow progeny (Craig et al., 2019). However, these primiparous animals make up a large proportion of progeny in any growing commercial herd (Smits, 2011). Therefore, it is imperative to enhance the reproduction performance of primiparous sows, including litter size and weight, milk production, and so on, to improve overall pig production.

Sow milk is the sole source of nutrition for the early growth, development, and health of piglets. However, limited information is available about the LF concentration in porcine milk during lactation and no data are available on whether genetic background or litter size can affect the LF concentration in porcine milk. The objectives of this study were (1) to determine the concentration of LF in porcine milk over the course of lactation, (2) to compare the concentration of LF between gilts and sows, and (3) to confirm if genetic background and litter size influence LF concentration in porcine milk.

\section{MATERIALS AND METHODS}

All experimental procedures using animals were approved by the Animal Care and Ethics Committee of Charles Sturt University, Wagga Wagga, New South Wales, Australia (protocol no. A18015).

\section{Animals}

Milk samples were collected from 30 primiparous (first parity sows/gilts) and 35 multiparous (ranging from second to ninth parity) sows. The animals were randomly chosen from 3 breeds, namely Landrace, Large White, and Duroc from the Pig Improvement Company, Grong Grong, New South Wales, Australia. The breed lines 2 and 3 represent purebred Landrace and Large White, respectively, selected predominantly on dam characteristics such as litter size, number of stillborn, birth and weaning weight, pre-weaning survival, teat number, and wean-to-estrus interval. The breed lines 9,16 , and 61 , however, represent purebred Large White, Duroc, and Landrace, respectively, selected predominantly on sire characteristics such as feed intake. This means dam line selection is for lines that have predominantly maternal characteristics in their selection parameters, whereas sire line selection only has progeny performance as a major selection parameter. The pigs' feeding procedure and the nutritional composition of the commercial pig feed were the same as our previous report (Jahan et al., 2016; Table 1). All animals had access to water ad libitum and were housed under standard commercial production conditions.

\section{Sample Collection}

Porcine milk collection was done using our published method (Jahan et al., 2016). Briefly, samples of $\sim 3$ to $5 \mathrm{~mL}$ of milk were collected in plastic, sterile vials by manual expression during milk letdown at 3 time points of lactation. The right or left side teats were selected based on availability. Colostrum was collected within $24 \mathrm{~h}$ postpartum, transition milk at d 3 , and mature milk at d 15 of lactation. All samples were collected at 
the same time of day (0900-1200 h) and were stored at $-20^{\circ} \mathrm{C}$ until analysis.

The porcine mammary gland does not have cisternae for storage of milk like dairy cows. Therefore, the milk collection from sows can only be performed once the milk ejection reflex is induced through the release of oxytocin after suckling of the teats by piglets for at least a minute (Fraser, 1980; Hartmann and Holmes, 1989). Sows nurse piglets about 20 times/day and the milk flow lasts for only about 10 to $20 \mathrm{~s}$ (Fraser, 1980; Hartmann and Holmes, 1989; Jahan et al., 2016). In this study, milk samples were collected after the milk letdown was induced by the suckling stimulus from piglets during the 10 - to 20 -s window of opportunity.

\section{Sample Preparation for Ultra-High-Performance Liquid Chromatography}

The milk samples were prepared according to the method of Dračková et al. (2009). Briefly, $1 \mathrm{~mL}$ of milk sample was defatted by centrifugation at $3,000 \times g$ at $4^{\circ} \mathrm{C}$ for $15 \mathrm{~min}$. Then the sample was precipitated by adding about $45 \mu \mathrm{L}$ of $1 \mathrm{~mol} / \mathrm{L} \mathrm{HCl}$ to a $\mathrm{pH} 4.6$ to separate the whey. Following centrifugation at 3,000 $\times$ $g$ for 15 min at $4^{\circ} \mathrm{C}$, the supernatant whey was collected into a separate tube and stored at $-20^{\circ} \mathrm{C}$ until analysis by ultra-high-performance liquid chromatography (UHPLC).

Table 1. Nutritional composition of commercial pig feed for primiparous and multiparous sows fed during gestation and lactation $(\mathrm{DE}=$ digestible energy $)$

\begin{tabular}{lrr}
\hline Nutrient & $\begin{array}{c}\text { Lactating } \\
\text { sow }\end{array}$ & $\begin{array}{c}\text { Pregnant } \\
\text { sow }\end{array}$ \\
\hline Pig DE, MJ/kg & 14.1 & 13.0 \\
Pig ME, Mcal/kg & 3.2 & 3.0 \\
Moisture, \% & 9.2 & 9.6 \\
CP, \% & 17.9 & 14.3 \\
Lysine, \% & 1.1 & 0.8 \\
Methionine, \% & 0.3 & 0.3 \\
Methionine+ cystine, \% & 0.7 & 0.6 \\
Threonine, \% & 0.7 & 0.6 \\
Isoleucine, \% & 0.8 & 0.6 \\
Leucine, \% & 1.3 & 1.0 \\
Tryptophan, \% & 0.2 & 0.2 \\
Arginine, \% & 1.2 & 0.9 \\
Histidine, \% & 0.5 & 0.4 \\
Valine, \% & 0.9 & 0.7 \\
Available lysine, \% & 0.9 & 0.7 \\
Crude fat, \% & 5.5 & 5.5 \\
Crude fiber, \% & 4.8 & 6.3 \\
Ash, \% $\%$ & 6.0 & 6.9 \\
Calcium, \% & 0.9 & 1.1 \\
Available phosphorus, \% & 0.4 \\
Total phosphorus, \% & 0.4 & 0.9 \\
Salt, \% $\%$ & 0.8 & 0.4 \\
Sodium, \% & 0.3 & 0.2 \\
Chloride, \% & 0.1 & 0.2 \\
Choline, mg/kg & 0.2 & $1,598.5$ \\
\hline
\end{tabular}

\section{Quantitative Determination of LF in the Milk Samples by UHPLC}

The LF in the supernatant whey samples was quantitatively analyzed using the modified method of Yao et al. (2013), through an Agilent 1290 Infinity system (Agilent Technologies, Santa Clara, CA) with a diode array UV detector (1260 DAD, serial no. G4212B, Agilent Technologies) with a C18 HPLC column (Jupiter 5u C18 300R, 250_4.6 mm, 5 mm, Phenomenex, Torrance, $\mathrm{CA}$ ) at $37^{\circ} \mathrm{C}$. The mobile phase consisted of A: $0.1 \%$ trifluoroacetic acid in $95 \%$ water and $5 \%$ acetonitrile (vol/vol) and B: $0.1 \%$ trifluoroacetic acid in $5 \%$ water and $95 \%$ acetonitrile (vol/vol). The LF was eluted from the prepared sample using an isocratic elusion from $35 \%$ mobile phase B for 1 min and then a linear gradient to $60 \%$ mobile phase B for $19 \mathrm{~min}$ and finally $10 \mathrm{~min}$ (post time) for equilibration. A constant flow rate at $0.5 \mathrm{~mL} / \mathrm{min}$ and an injection volume of $40 \mathrm{~mL}$ was used. The auto sampler temperature was held constant at $4^{\circ} \mathrm{C}$. Absorbance was measured at a wavelength of $210 \mathrm{~nm}$. Data acquisition was performed using the MassHunter Workstation Software (version B.08.0, Agilent Technologies, Santa Clara, CA). The level of milk LF was quantified by comparison with a standard curve prepared using commercial bovine LF standard (Cerilliant, purity $98.12 \mathrm{wt} \%$, Sigma-Aldrich, St. Louis, MO; Figure 1). All samples were analyzed in duplicate. The final concentration of LF was expressed as milligrams per milliliter of milk.

\section{Method Validation}

The method was validated by evaluation of specificity, linearity, sensitivity, repeatability, recovery, and precision (intra- and inter-day). The specificity was demonstrated by comparing the retention time of the bovine milk LF standard, natural bovine milk, and a

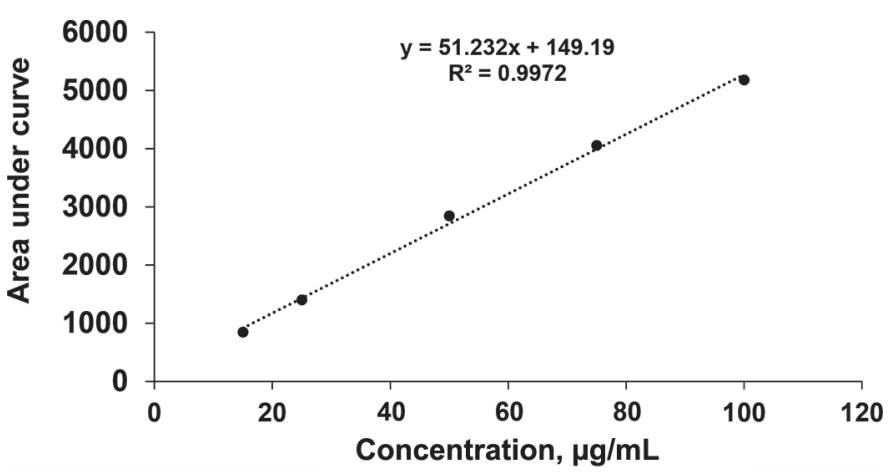

Figure 1. Standard curve obtained from the relative peak area of 6 different concentrations of internal bovine lactoferrin standard in ultra-high-performance liquid chromatography. 
blank sample. A standard curve was obtained by using 5 different concentrations of LF in the range of 15 to 100 $\mu \mathrm{g} / \mathrm{mL}$. The slope, intercept, and linearity of the standard curve were evaluated by linear regression analysis (Figure 1). Sensitivity was determined by evaluation of the limit of detection and limit of quantification at a signal-to-noise ratio of $3: 1$ and 10:1, respectively. The limit of detection and limit of quantification were 1 and $5 \mu \mathrm{g} / \mathrm{mL}$, respectively. Repeatability was evaluated by calculating the percentage of relative standard deviation (RSD) of samples at low, medium, and high concentration levels on the same day. The RSD varied from 2.5 to $5.6 \%$, which demonstrated that the method was reproducible. Recovery of this assay was evaluated by applying the standard addition method. Comparison was made between the results for the directly injected LF standards and the results for the spiked bovine milk samples with the same standards. The recovery rate was calculated using the following formula: recovery rate $=$ (measured value in the spiked milk samples original level of LF in the milk)/spiked value $\times 100$. The recovery rate was $95.9 \%$. Intra-day precision was evaluated by 10 replicate analyses of each sample with 3 different concentration levels on the same day. On the other hand, for inter-day precision, the same samples were prepared and analyzed on 7 consecutive days. Precision was calculated in terms of RSD, which was 2.7 to $6.3 \%$ and 2.4 to $7.2 \%$ for intra-day and inter-day, respectively.

\section{Confirmation of the Porcine LF by Protein Gel Electrophoresis}

Because the standard for porcine milk LF is not yet commercially available in the market, we used the commercially available bovine milk LF standard instead. Due to the species difference, the retention time of the porcine milk LF at UHPLC was found to be slightly different from that of the bovine milk LF standard (Figure 2). Therefore, we confirmed porcine milk LF by protein gel electrophoresis on polyacrylamide under denaturing conditions (SDS-PAGE). A total of 6 chromatographic peaks were separated and collected based on different retention time of porcine milk LF using the UHPLC system (Figures 1 and 3). Each peak represents the detector response for a different component. Samples including 6 chromatographic peaks, bovine LF standard, and diluted porcine milk were mixed with $2 \times$ loading dye (Tris-Glycine SDS, Novex, Thermo Fisher Scientific, Waltham, MA) at a ratio of $1: 1$, and heated for $10 \mathrm{~min}$ at $95^{\circ} \mathrm{C}$. Twenty microliters was loaded on to the precast SDS-PAGE gels (Bolt Mini Gel in $1 \mathrm{x}$ Bolt MES SDS running buffer, Novex, Thermo Fisher
Scientific) running at a constant voltage of $165 \mathrm{~V}$. The gels were fixed and stained in Coomassie blue dye (containing 40\% ethanol, 10\% glacial acetic acid, and 0.2\% Coomassie Brilliant Blue R-250; Fairbanks et al., 1971) for $5 \mathrm{~min}$ at room temperature with gentle shaking. Then de-staining of the gels was performed in a solution containing $10 \%$ ethanol and $10 \%$ glacial acetic acid with gentle shaking for at least $30 \mathrm{~min}$ at room temperature. The protein marker used in this assay was an unstained mixture of 10 Strep-tagged, recombinant proteins (10-250 kD; Precision Plus Protein, Bio-Rad, Hercules, CA). Image Lab 6.0.1 software for Windows (Bio-Rad) was used for imaging. The fraction that produced a band close to the average molecular weight of LF ( 78,000 Da) and close to the band for standard bovine LF was considered as the LF fraction of porcine milk (Figure 2).

\section{Statistical Analysis}

The results presented in this study are based on a linear mixed effect regression model to allow for analyzing the repeated measures data. The response variable is the logarithmic-transformed concentration of LF. The data were log-transformed to achieve normality and constant variance. Fixed effects in the model were time point of lactation (colostrum, transitional milk, mature milk), parity (gilt, sow), breed/breed line (Landrace, Duroc, Large White B2, B3, B9, B16, B61), and litter size (total number of piglets born, as a covariate), with the interactions of parity, breed/breed line, and litter size with lactation time point also included in the model. Animal ID was included as a random effect to allow for repeated measure on an animal. Bonferroni corrections were used to adjust for pairwise comparisons. The analysis was conducted using IBM SPSS statistical software, Version 25.0 (IBM Corp., Armonk, NY). The differences in means were considered statistically significant if the associated $P$-value was less than 0.05 .

\section{RESULTS}

\section{Changes in Porcine Milk LF Concentration During the Course of Lactation}

The LF concentration in porcine milk at 3 different stages of lactation is summarized in Figure 4. The concentration of LF was the highest in the colostrum and gradually declined during the course of lactation. In the transitional milk and mature milk, only $\sim 38 \%$ and $\sim 33 \%$ of the initial concentration of LF was present, respectively. The overall difference in LF concentration 

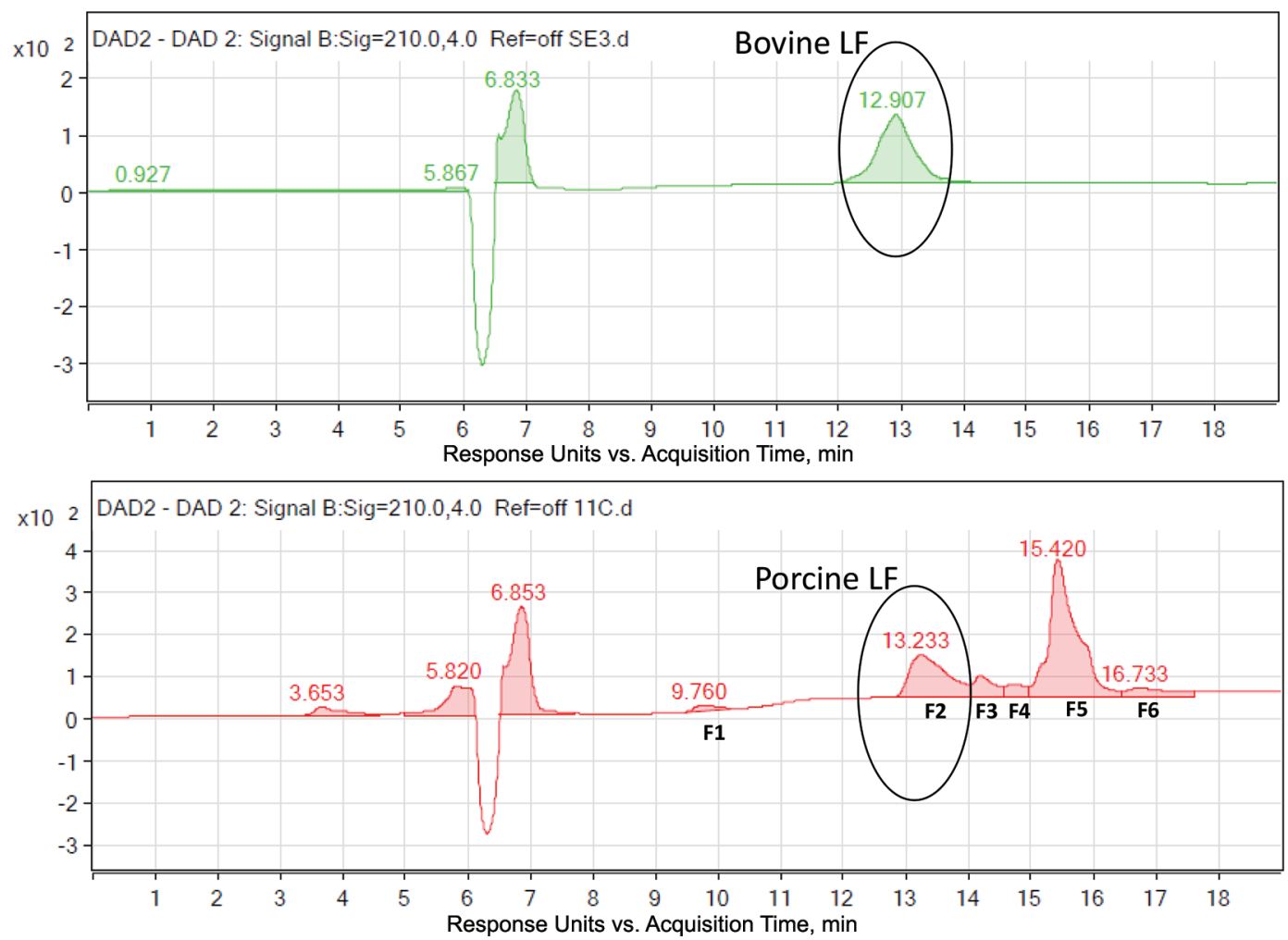

Figure 2. Ultra-high-performance liquid chromatography trace with the retention times of the peaks observed for bovine lactoferrin (LF) standard and porcine milk LF. F1 to F6 represent fraction 1 to 6 , respectively. DAD $2=$ diode array detection 2 ; Sig $=$ signal; Ref. $=$ reference number of sample.

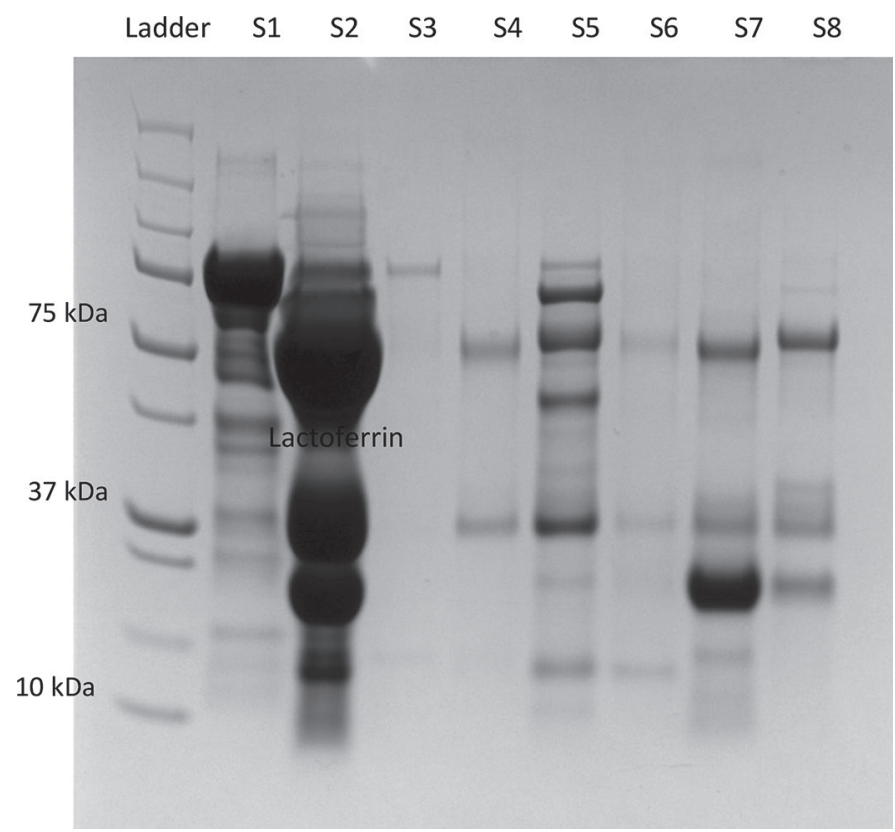

Figure 3. Confirmation of lactoferrin (LF) in the ultra-high-performance liquid chromatography (UHPLC) fractions by SDS-PAGE. Samples loaded onto each lane are as follows: S1 = diluted porcine whole milk sample; $\mathrm{S} 2=$ bovine LF standard; $\mathrm{S} 3$ to $\mathrm{S} 8=\mathrm{UHPLC}$ fractions from 1 to 6 . The top band in $\mathrm{S} 4$ was identified as LF. between the stages of lactation was highly significant, both colostrum versus transitional milk $(P<0.001)$ and colostrum versus mature milk $(P<0.001)$. Also, the difference in LF concentration tended toward significance between the transitional and mature milk $(P$ $=0.08)$.

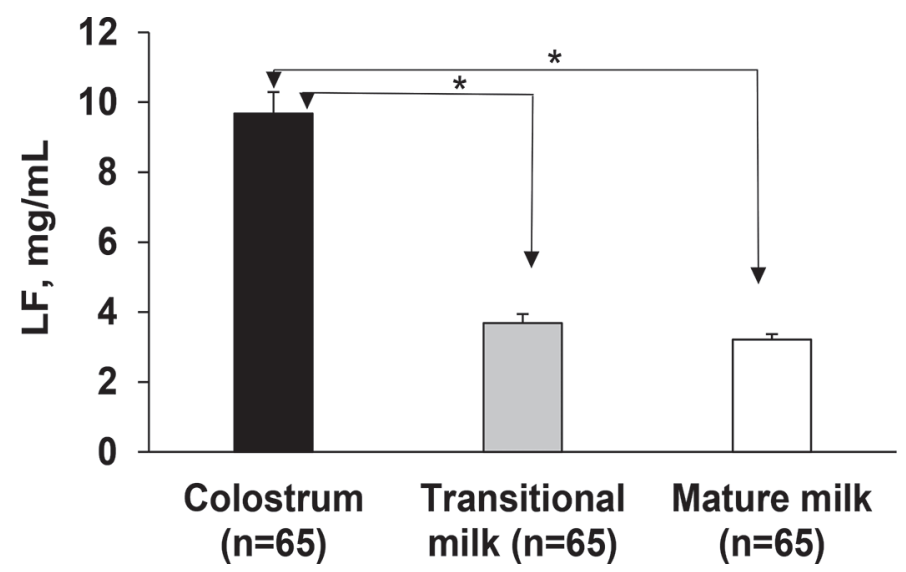

Figure 4. Concentration of lactoferrin (LF) in porcine colostrum, transitional milk, and mature milk. Values are mean $\pm \mathrm{SEM}$. ${ }^{*} P$-value $<0.05$ between the 2 stages of lactation. 


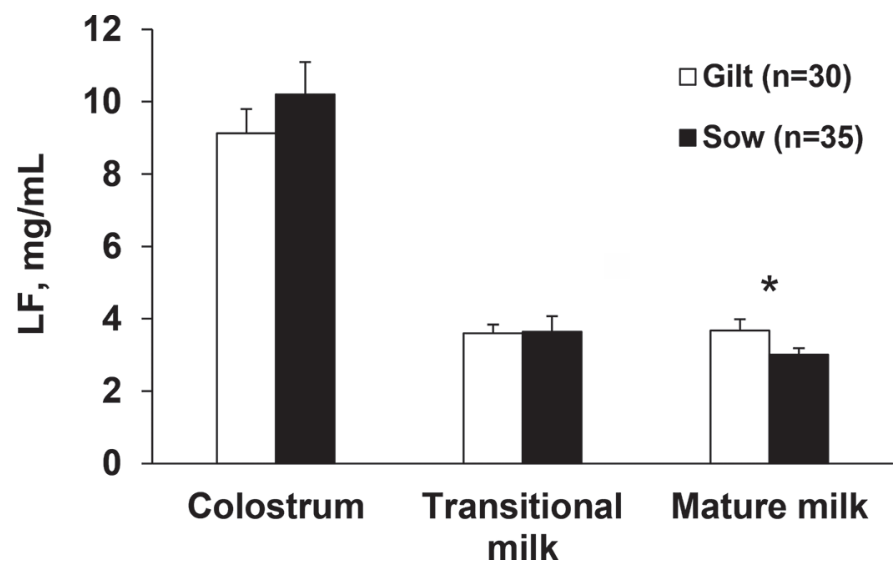

Figure 5. Comparison between gilts and sows for the concentration of lactoferrin in colostrum, transitional milk, and mature milk. Values are mean \pm SEM. ${ }^{*} P$-value $<0.05$ between gilts and sows.

\section{Comparison of Milk LF Concentration Between Multiparous Sows and Gilts}

The comparison of milk LF concentration between primiparous and multiparous sows throughout lactation is presented in Figure 5. Gilt milk contained $\sim 10 \%$ and $\sim 1 \%$ lower concentrations of LF in colostrum and transition milk, respectively, compared with those of sow milk $(P>0.05)$; however, the LF concentration of gilt mature milk was $\sim 22 \%$ higher than that of sow milk $(P<0.05)$.

\section{Effect of Breed/Breed Line and Litter Size on Porcine Milk LF Concentration}

According to our study, the breed line had an overall significant effect $(P<0.05$, Figures $6 \mathrm{~B}, 6 \mathrm{D}$, and $6 \mathrm{~F})$ on the porcine milk LF concentration; however, no significant difference was observed when breed was considered $(P>0.05$; Figure $6 \mathrm{~A}, 6 \mathrm{C}$, and $6 \mathrm{E})$. In the case of colostrum, breed line 16 had the highest content of LF followed by breed line 61, whereas breed line 61 had the highest LF concentration in both transitional and mature milk compared with the other breed lines of pigs (Figure 6D and 6F). Breed line 16 had a significant $\sim 28$ to $39 \%$ higher concentration of LF in colostrum compared with breed line 2, 3, 9, and $61(P<0.05$, Figure 6B). Additionally, breed line 61 had a significant $\sim 34$ to $54 \%$ higher concentration of LF in mature milk compared with all other breed lines $(P<0.05$, Figure $6 \mathrm{~F})$. In transitional milk, however, the difference in LF concentration between breed line 6 and 61 was marginally significant $(P=0.06$, Figure $6 \mathrm{D})$. Interestingly, in contrast to the usual declining trend of LF concentration throughout lactation, both breed line 61 and 6 had a relatively higher concentration of LF in mature milk compared with transitional milk. Litter size (data not shown) did not have any significant effect on the LF concentration of porcine milk during lactation.

\section{DISCUSSION}

Pig producers have high loss in the first week after parturition, with the highest morbidity and mortality related to malnutrition and scours (Wheeler et al., 2001). Porcine milk is a unique feed for piglets from birth and functionally supports their growth and development physiology (Barber et al., 1955; Prunier et al., 2010). Milk LF has multiple biological functions including protection against pathogenic infection and optimizing growth and development of newborns; therefore, the determination of how the concentration of LF changes during the various stages of lactation is very important in pig production and health (Hurley, 2001). In this study, using the validated UHPLC method, we demonstrated that the highest concentrations of LF were found in colostrum, followed by transitional milk and then mature milk. Our findings are consistent with earlier studies where a declining trend in LF concentration was observed during the course of lactation (Elliot et al., 1984; Yang et al., 2000; Table 2). Rai et al. (2014) also reported that LF content in humans was the highest in colostrum and decreased by about $50 \%$ during the first $5 \mathrm{~d}$ of lactation. However, Yang et al. (2000) suggests that a slow decline occurs in the concentration of LF in porcine milk, especially in the first week of lactation. The decline in LF concentration from colostrum to transitional and mature milk may be due to a lower rate of protein production or increased dilution of LF (or both) during milk production caused by an increased synthesis of milk. Contrary to human and porcine milk, in bovine milk it was observed that the mean LF concentration was higher in the later lactation period than in the earlier or middle periods (Hagiwara et al., 2003; Cheng et al., 2008).

The concentration of porcine milk LF in our study was higher than that of previous reports (Elliot et al., 1984; Yang et al., 2000). This may be due to variations in the method of milk sample collection (with/without the use of oxytocin), preparation and quantification among studies. In a global, systematic review, Rai et al. (2014) reported a similar variation in LF concentration of human milk based on the method of quantification among studies. Our study used a highly sensitive and specific quantitative analysis method - UHPLC, compared with the radial immunodiffusion and ELISA methods used in earlier studies. We summarized the LF concentrations in human, bovine and porcine milk using different analytical methods reported previously (Table 2). The summary shows that the concentration 
A

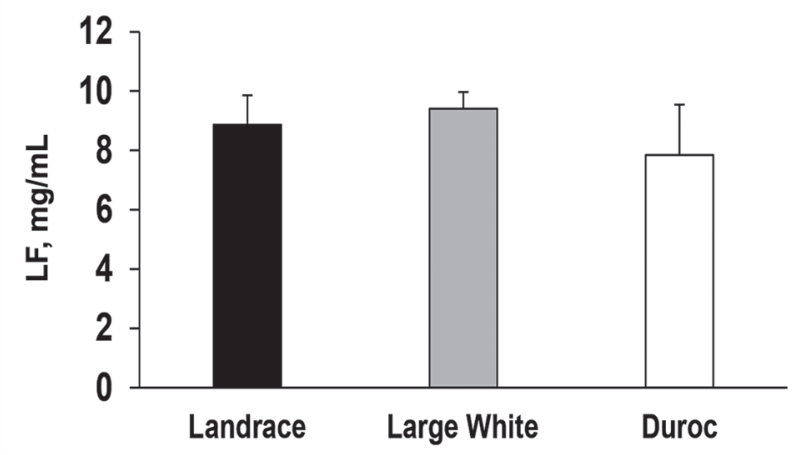

C

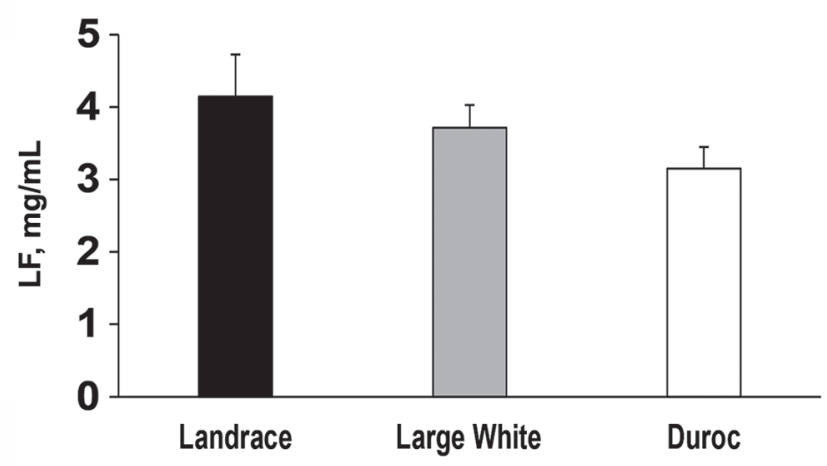

$\mathbf{E}$

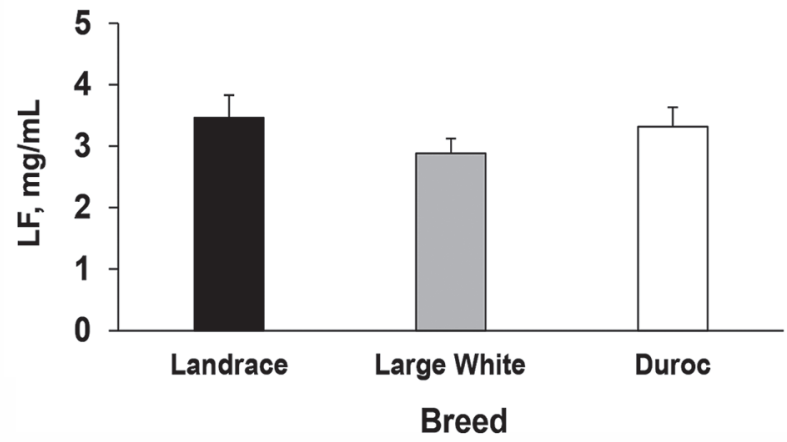

B

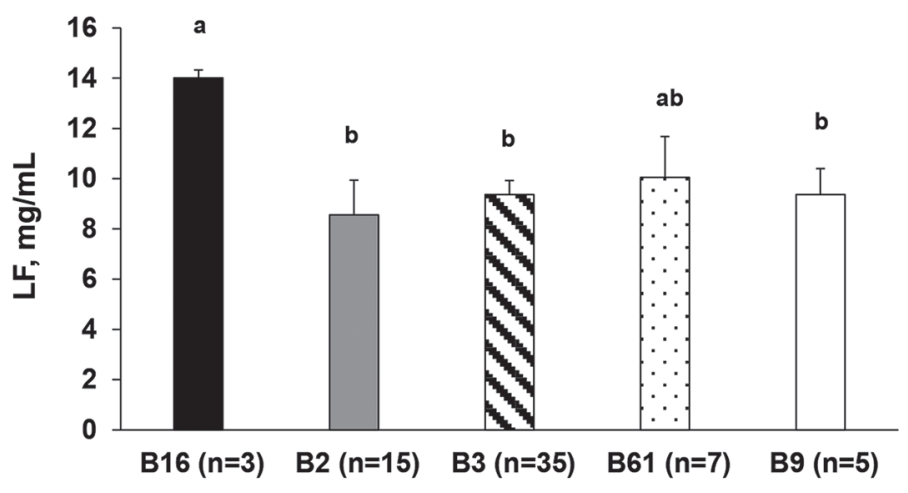

D

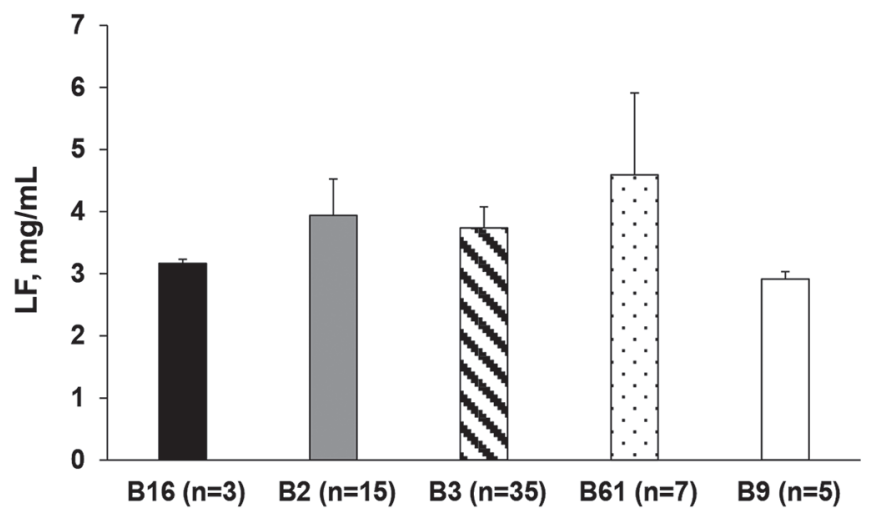

F

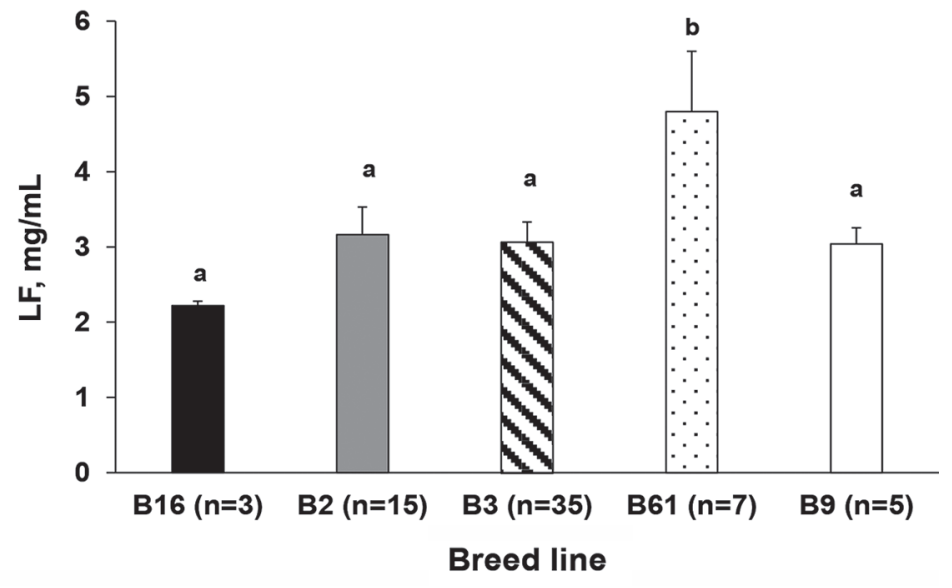

Figure 6. Comparison among different breeds and breed lines for the concentration of lactoferrin (LF) in porcine milk during lactation. Colostrum $(\mathrm{A}$ and $\mathrm{B})$, transitional milk $(\mathrm{C}$ and $\mathrm{D})$, and mature milk $(\mathrm{E}$ and $\mathrm{F})$. Values are mean \pm SEM. Different letters $(\mathrm{a}, \mathrm{b})$ indicate $\mathrm{a}$ significant difference between groups $(P<0.05)$.

of bovine milk LF in the HPLC method was about 2 times higher than that of either the ELISA or radial immunodiffusion methods (Table 2). Moreover, there was a huge variation in LF concentration of human milk based on geographical location (Rai et al., 2014). To the best of our knowledge, qualitative analysis of LF concentration in porcine milk during lactation using the UHPLC method has not been previously reported. 


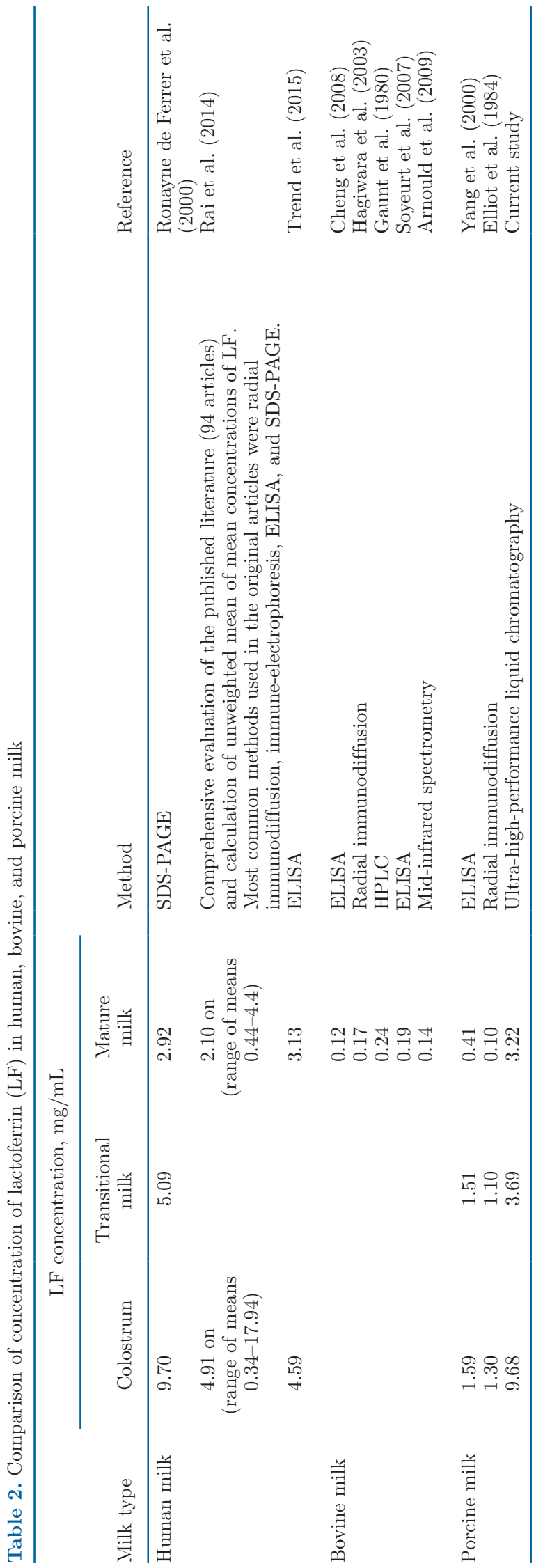

Interestingly, according to the findings of this study, the mean concentration of LF in porcine milk is very close to that of human milk (Ronayne de Ferrer et al., 2000). We also reported a comparable concentration of sialic acid between pig milk and human milk (Jahan et al., 2016). These 2 findings further justify that piglets are an ideal animal model for human infants.

Regarding the effect of parity on milk LF concentration, Cheng et al. (2008) reported higher concentrations of LF in parities 3, 4, and 5 compared with parity 1 and 2 in cattle. However, in humans, the parity of the mother did not seem to have an effect on the concentration of LF (Rai et al., 2014), suggesting that the effect of milk LF concentration on parity number is species specific. To our knowledge, the effect of parity on porcine milk LF concentration has not been previously reported. We found that the gilts (primiparous sows) had significantly higher concentrations of LF in the mature milk compared with multiparous sows $(P$ $<0.05)$. A possible explanation behind this finding is that, in the commercial pig industry, gilts are included in the production system as soon as they attain puberty, even before they attain a mature BW. Thus, they might have a relatively low capacity to produce the same levels of milk as fully mature sows (Lee and Kim, 2006). Also, gilts normally produce a high rate of IURG piglets compared with mature sows (McMillen and Robinson, 2005). As a compensatory response by the body, the gilts may then attempt to produce relatively higher levels of LF in mature milk to help compensate for deficiencies in milk volume, to support their piglets' proper growth and development-particularly IUGR piglets, who demand more milk LF to speed up growth and development in early life. Further studies are required to demonstrate the underlying molecular mechanism.

To the best of our knowledge, this is the first study to determine the effect of genetic background on LF concentration in porcine milk. Although, there was no effect of breed on porcine milk LF concentration, breed line had a significant influence on the LF concentration of porcine milk. Similarly, the influence of genetic background was also reported in the case of bovine milk (Tsuji et al., 1990; Soyeurt et al., 2007). These studies reported that Jersey cows had significantly higher concentrations of LF in both colostrum (Tsuji et al., 1990) and mature milk than Holstein cows (Soyeurt et al., 2007). Among the 5 breed lines in our experiment, the sows from breed line 16 contained the highest LF concentration in colostrum, whereas the breed line 61 sows had the highest LF concentration in mature milk. Possible reasons for this include variation in the ability of synthesis and secretion of milk LF in the mammary gland cells, and variation of protein and fat percentage 
and SCS in the milk of sows among different breeds of female pigs. Lactoferrin concentration was found to be positively correlated with the milk protein and fat percentage and, to a lesser extent, with the SCS (Arnould et al., 2009). Thus our findings suggest that breed line 16 and breed line 61 might have the potential to ensure better immunity, growth, and development for their offspring based on the higher LF content in milk (Chen et al., 2015; Jahan et al., 2017), which in turn can play a significant role in the survival of piglets. However, a limitation of this study is that the number of pigs from the Duroc and Mixed breeds and also from breed lines 9 and 16 was very small. Therefore, further study with a larger number of pigs from each breed is recommended to confirm our findings.

An earlier study has demonstrated the beneficial effects of supplementing preterm piglets with 0.1 to 1 $\mathrm{g} / \mathrm{d}$ of bovine milk derived LF on intestinal growth, development, and protection from disease (Nguyen et al., 2014). However, supplementation of LF to mixed parity sows at $2 \mathrm{~g} / \mathrm{d}$ from late gestation to weaning did not improve lactation performance (Liu et al., 2019). Therefore, dose and duration are 2 important factors that need to be considered during LF supplementation. Though, there is a potential for the use of LF as a functional ingredient to boost health and production in the swine industry. Piglets born from gilts have been shown to have poor growth and development compared with those born from multiparous sows (Craig et al., 2017). A key finding of this study is that sow milk contains high concentrations of LF, which may play an important role on optimizing immune function, growth, and development of piglets. The findings of LF concentration in sow milk also can guide a new functional feed (i.e., a milk replacer) development for low birth weight piglets to improve health and production outcomes for the industry overall.

\section{ACKNOWLEDGMENTS}

We greatly acknowledge Phakamile Ntombela for her help with sample collection. We thank bio-statistician Gang Xie (Quantitative Consulting Unit, Charles Sturt University, Wagga Wagga, NSW, Australia) for his advice on statistical analysis. We also thank all staff at the Pig Improvement Company Grong Grong piggery, in particular manager Robert Johnston, for their support and help during sample collection. The authors declare that there is no conflict of interest.

\section{REFERENCES}

Arnould, V. M., H. Soyeurt, N. Gengler, F. Colinet, M. Georges, C. Bertozzi, D. Portetelle, and R. Renaville. 2009. Genetic analysis of lactoferrin content in bovine milk. J. Dairy Sci. 92:2151-2158. https://doi.org/10.3168/jds.2008-1255.

Barber, R. S., R. Braude, and K. G. Mitchell. 1955. Studies on milk production of Large White pigs. J. Agric. Sci. 46:97-118. https:// doi.org/10.1017/S0021859600039654.

Cebulska, A., W. Kapelański, and K. Frątczak. 2012. Breeding and production of pigs in Poland. Res. Pig Breed. 6:13-16.

Chen, Y., Z. Zheng, X. Zhu, Y. Shi, D. Tian, F. Zhao, N. Liu, P. S. Hüppi, F. A. Troy II, and B. Wang. 2015. Lactoferrin promotes early neurodevelopment and cognition in postnatal piglets by upregulating the BDNF signaling pathway and polysialylation. Mol. Neurobiol. 52:256-269. https://doi.org/10.1007/s12035-014-8856 -9 .

Cheng, J., J. Wang, D. Bu, G. Liu, C. Zhang, H. Wei, L. Zhou, and J. Wang. 2008. Factors affecting the lactoferrin concentration in bovine milk. J. Dairy Sci. 91:970-976. https://doi.org/10.3168/jds .2007-0689.

Craig, J. R., C. L. Collins, K. L. Bunter, J. J. Cottrell, F. R. Dunshea, and J. R. Pluske. 2017. Poorer lifetime growth performance of gilt progeny compared with sow progeny is largely due to weight differences at birth and reduced growth in the preweaning period, and is not improved by progeny segregation after weaning. J. Anim. Sci. 95:4904-4916. https://doi.org/10.2527/jas2017.1868.

Craig, J. R., F. R. Dunshea, J. J. Cottrell, J. B. Furness, U. A. Wijesiriwardana, and J. R. Pluske. 2019. A comparison of the anatomical and gastrointestinal functional development between gilt and sow progeny around birth and weaning. J. Anim. Sci. 97:38093822. https://doi.org/10.1093/jas/skz217.

Dračková, M., I. Borkovcova, B. Janštová, M. Naiserova, H. Přidalová, P. Navratilova, and L. Vorlova. 2009. Determination of lactoferrin in goat milk by HPLC method. Czech J. Food Sci. 27:S102-S104. https://doi.org/10.17221/944-CJFS.

Elliot, J., B. Senft, G. Erhardt, and D. Fraser. 1984. Isolation of lactoferrin and its concentration in sows' colostrum and milk during a 21-day lactation. J. Anim. Sci. 59:1080-1084. https://doi.org/10 $.2527 /$ jas1984.5941080x.

Fairbanks, G., T. L. Steck, and D. Wallach. 1971. Electrophoretic analysis of the major polypeptides of the human erythrocyte membrane. Biochemistry 10:2606-2617. https://doi.org/10.1021/ bi00789a030.

Fraser, D. 1980. A review of the behavioural mechanism of milk ejection of the domestic pig. Appl. Anim. Behav. Sci. 6:247-255. https: //doi.org/10.1016/0304-3762(80)90026-7.

Gallagher, D. P., P. F. Cotter, and D. M. Mulvihill. 1997. Porcine milk proteins: A review. Int. Dairy J. 7:99-118. https://doi.org/10 .1016/S0958-6946(96)00056-8.

Gaunt, S., N. Raffio, E. Kingsbury, R. Damon Jr., W. Johnson, and B. Mitchell. 1980. Variation of lactoferrin and mastitis and their heritabilities. J. Dairy Sci. 63:1874-1880. https://doi.org/10.3168/ jds.S0022-0302(80)83154-7.

Giacinti, G., L. Basiricò, B. Ronchi, and U. Bernabucci. 2013. Lactoferrin concentration in buffalo milk. Ital. J. Anim. Sci. 12:e23. https://doi.org/10.4081/ijas.2013.e23.

González-Chávez, S. A., S. Arévalo-Gallegos, and Q. Rascón-Cruz. 2009. Lactoferrin: Structure, function and applications. Int. J. Antimicrob. Agents 33:e301-e308.

Groves, M. L. 1960. The isolation of a red protein from milk. J. Am. Chem. Soc. 82:3345-3350. https://doi.org/10.1021/ja01498a029.

Hagiwara, S.-i., K. Kawai, A. Anri, and H. Nagahata. 2003. Lactoferrin concentrations in milk from normal and subclinical mastitic cows. J. Vet. Med. Sci. 65:319-323. https://doi.org/10.1292/jvms .65.319.

Hartmann, P. E., and M. A. Holmes. 1989. Sow lactation. Pages 72-97 in Manipulating Pig production II. Proceedings of the Biennial Conference of the Australasian Pig Science Association (APSA). J. L. Barnett and D. P. Hennessy, ed. Australasian Pig Science Association, Albury, Australia.

Hiss, S., T. Meyer, and H. Sauerwein. 2008. Lactoferrin concentrations in goat milk throughout lactation. Small Rumin. Res. 80:87-90. https://doi.org/10.1016/j.smallrumres.2008.07.027. 
Hurley, W. L. 2001. Mammary gland growth in the lactating sow. Livest. Prod. Sci. 70:149-157. https://doi.org/10.1016/S0301 -6226(01)00208-1.

Jahan, M., S. Kracht, Y. Ho, Z. Haque, B. N. Bhattachatyya, P. C. Wynn, and B. Wang. 2017. Dietary lactoferrin supplementation to gilts during gestation and lactation improves pig production and immunity. PLoS One 12:e0185817. https://doi.org/10.1371/ journal.pone. 0185817 .

Jahan, M., P. Wynn, and B. Wang. 2016. Molecular characterization of the level of sialic acids N-acetylneuraminic acid, N-glycolylneuraminic acid, and ketodeoxynonulosonic acid in porcine milk during lactation. J. Dairy Sci. 99:8431-8442. https://doi.org/10.3168/jds .2016-11187.

Konuspayeva, G., B. Faye, G. Loiseau, and D. Levieux. 2007. Lactoferrin and immunoglobulin contents in camel's milk (Camelus bactrianus, Camelus dromedarius, and hybrids) from Kazakhstan. J. Dairy Sci. 90:38-46. https://doi.org/10.3168/jds.S0022 -0302(07)72606-1.

Lee, J.-Y., and I.-H. Kim. 2006. Advancing parity is associated with high milk production at the cost of body condition and increased periparturient disorders in dairy herds. J. Vet. Sci. 7:161-166. https://doi.org/10.4142/jvs.2006.7.2.161.

Liu, F., J. Hogg, S. Kracht, C. Brewster, D. Henman, R. Athorn, R. Morrison, R. Smits, and R. Campbell. 2019. Supplementing 2 $\mathrm{g} / \mathrm{d}$ bovine lactoferrin from late gestation until weaning did not improve lactation performance of mixed parity sows. Anim. Prod. Sci. 59:2191-2195. https://doi.org/10.1071/AN18286.

Manzoni, P., I. Stolfi, H. Messner, S. Cattani, N. Laforgia, M. G. Romeo, L. Bollani, M. Rinaldi, E. Gallo, M. Quercia, M. Maule, M. Mostert, L. Decembrino, R. Magaldi, F. Mosca, F. Vagnarelli, L. Memo, P. M. Betta, M. Stronati, and D. Farina. 2012. Bovine lactoferrin prevents invasive fungal infections in very low birth weight infants: A randomized controlled trial. Pediatrics 129:116123. https://doi.org/10.1542/peds.2011-0279.

Masson, P., and J. Heremans. 1971. Lactoferrin in milk from different species. Comp. Biochem. Physiol. B 39:119-129.

McMillen, I. C., and J. S. Robinson. 2005. Developmental origins of the metabolic syndrome: Prediction, plasticity, and programming. Physiol. Rev. 85:571-633. https://doi.org/10.1152/physrev.00053 .2003.

Nguyen, D. N., Y. Li, P. T. Sangild, S. B. Bering, and D. E. Chatterton. 2014. Effects of bovine lactoferrin on the immature porcine intestine. Br. J. Nutr. 111:321-331. https://doi.org/10.1017/ S0007114513002456.

Prunier, A., M. Heinonen, and H. Quesnel. 2010. High physiological demands in intensively raised pigs: Impact on health and welfare. Animal 4:886-898. https://doi.org/10.1017/S175173111000008X.

Rai, D., A. S. Adelman, W. Zhuang, G. P. Rai, J. Boettcher, and B. Lönnerdal. 2014. Longitudinal changes in lactoferrin concentrations in human milk: A global systematic review. Crit. Rev. Food Sci. Nutr. 54:1539-1547. https://doi.org/10.1080/10408398.2011 .642422 .

Ronayne de Ferrer, P. A., A. Baroni, M. E. Sambucetti, N. E. López, and J. M. Ceriani Cernadas. 2000. Lactoferrin levels in term and preterm milk. J. Am. Coll. Nutr. 19:370-373. https://doi.org/10 $.1080 / 07315724.2000 .10718933$.

Smits, R. 2011. Impact of the sow on progeny productivity and herd feed efficiency. Recent Advances In Animal Nutrition-Australia 18:61-67.

Somm, E., P. Larvaron, Y. van de Looij, A. Toulotte, A. Chatagner, M. Faure, S. Métairon, R. Mansourian, F. Raymond, R. Gruetter,
B. Wang, S. V. Sizonenko, and P. S. Hüppi. 2014. Protective effects of maternal nutritional supplementation with lactoferrin on growth and brain metabolism. Pediatr. Res. 75:51-61. https://doi .org/10.1038/pr.2013.199.

Sorensen, M., and S. P. L. Sorensen. 1940. The proteins in whey. Compte rendu des Travaux du Laboratoire de Carlsberg. Ser. Chim. 23:55-99.

Soyeurt, H., F. Colinet, V.-R. Arnould, P. Dardenne, C. Bertozzi, R. Renaville, D. Portetelle, and N. Gengler. 2007. Genetic variability of lactoferrin content estimated by mid-infrared spectrometry in bovine milk. J. Dairy Sci. 90:4443-4450. https://doi.org/10.3168/ jds. 2006-827.

Trend, S., T. Strunk, J. Hibbert, C. H. Kok, G. Zhang, D. A. Doherty, P. Richmond, D. Burgner, K. Simmer, D. J. Davidson, and A. J. Currie. 2015. Antimicrobial protein and peptide concentrations and activity in human breast milk consumed by preterm infants at risk of late-onset neonatal sepsis. PLoS One 10:e0117038. https:// doi.org/10.1371/journal.pone.0117038.

Tsuji, S., Y. Hirata, F. Mukai, and S. Ohtagaki. 1990. Comparison of lactoferrin content in colostrum between different cattle breeds. J. Dairy Sci. 73:125-128. https://doi.org/10.3168/jds.S0022 -0302(90)78654-7.

Václavková, E., P. Daněk, and M. Rozkot. 2012. The influence of piglet birth weight on growth performance. Res. Pig Breed. 6:1-3.

Wang, B. 2016. Molecular determinants of milk lactoferrin as a bioactive compound in early neurodevelopment and cognition. J. Pediatr. 173:S29-S36. https://doi.org/10.1016/j.jpeds.2016.02.073.

Wang, B., Y. P. Timilsena, E. Blanch, and B. Adhikari. 2019. Lactoferrin: Structure, function, denaturation and digestion. Crit. Rev. Food Sci. Nutr. 59:580-596. https://doi.org/10.1080/10408398 .2017.1381583.

Wheeler, M., G. Bleck, and S. Donovan. 2001. Transgenic alteration of sow milk to improve piglet growth and health. Reprod. Suppl. $58: 313-324$

Wu, G., F. W. Bazer, J. M. Wallace, and T. E. Spencer. 2006. Intrauterine growth retardation: Implications for the animal sciences. J. Anim. Sci. 84:2316-2337. https://doi.org/10.2527/jas.2006-156.

Yang, C., X. Zhu, N. Liu, Y. Chen, H. Gan, F. A. Troy II, and B. Wang. 2014. Lactoferrin up-regulates intestinal gene expression of brain-derived neurotrophic factors BDNF, UCHL1 and alkaline phosphatase activity to alleviate early weaning diarrhea in postnatal piglets. J. Nutr. Biochem. 25:834-842. https://doi.org/ 10.1016/j.jnutbio.2014.03.015.

Yang, T. S., S. C. Wu, and S. R. Wang. 2000. Serum and milk lactoferrin concentration and the correlation with some blood components in lactating sows. Res. Vet. Sci. 69:95-97. https://doi.org/10.1053/ rvsc.2000.0393.

Yao, X., C. Bunt, J. Cornish, S. Y. Quek, and J. Wen. 2013. Improved RP-HPLC method for determination of bovine lactoferrin and its proteolytic degradation in simulated gastrointestinal fluids. Biomed. Chromatogr. 27:197-202. https://doi.org/10.1002/ bmc.2771.

\section{ORCIDS}

M. Jahan $\odot$ https://orcid.org/0000-0002-6370-0050

B. Wang $\odot$ https://orcid.org/0000-0003-2146-8529 